\title{
Inspiration Cards Workshops with Teachers in Early Co-Design Stages of Learning Analytics
}

\author{
FirstName Surname+ \\ Department Name \\ Institution/University Name \\ City State Country \\ email@email.com
}

\author{
FirstName Surname \\ Department Name \\ Institution/University Name \\ City State Country \\ email@email.com
}

\author{
FirstName Surname \\ Department Name \\ Institution/University Name \\ City State Country \\ email@email.com
}

\begin{abstract}
Despite the recognition of the need to include practitioners in the design of learning analytics (LA), especially teacher input tends to come later in the design process rather than in the definition of the initial design agenda. This paper presents a case study of a design project tasked with developing LA tools for a reading game for primary school children. Taking a co-design approach, we use the Inspiration Cards Workshop to ensure meaningful teacher involvement even for participants with low background in data literacy or experience in using learning analytics. We reflect on the process and findings to derive specific and transferable design principles that can guide the implementation of LA tools for primary school teachers in particular, and discuss opportunities and limitations of using the inspiration cards method that can inform future LA design efforts.
\end{abstract}

\section{CCS CONCEPTS}

- Human-centred Computing • Interaction Design • Interaction design process and methods $\bullet$ Participatory Design

\section{KEYWORDS}

Learning Analytics, co-design methods, inspiration cards, emerging technology

\section{ACM Reference format:}

FirstName Surname, FirstName Surname and FirstName Surname. 2018. Insert Your Title Here: Insert Subtitle Here. In Proceedings of the 10th International Conference on Learning Analytics and Knowledge (LAK '20). ACM, New York, USA, X pages. https://doi.org/10.1145/1234567890

\section{Introduction}

A strong seam of research has looked into the potential pedagogical

Article Title Footnote needs to be captured as Title Note

$\uparrow$ Author Footnote to be captured as Author Note

Permission to make digital or hard copies of part or all of this work for personal or classroom use is granted without fee provided that copies are not made or distributed for profit or commercial advantage and that copies bear this notice and the full citation on the first page. Copyrights for third-party components of this work must be honored. For all other uses, contact the owner/author(s).

LAK'20, March 23-27, 2020, Frankfurt, Germany

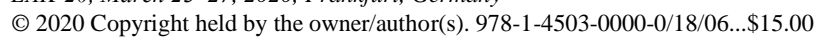

activities that Learning Analytics (LA) may support in classroom learning. Much of this research has engaged in theoretical work through the lens of education theories and existing concepts of educational practice (e.g. [26][31]). Design-oriented approaches where teachers and designers alike work together to uncover the opportunities of LA has been less common, but yet equally important [32]. Whereas theoretical perspectives can provide input into how LA might benefit teaching activities for example, they cannot always capture the complex realities of education practitioners or their visions of learning and teaching, nor can they empower them to become active participants providing input to the future direction of LA. Among the many barriers to the designoriented research have been the lack of design methods, especially for the early exploratory stages of the design process and for involving stakeholders with little understanding of the potential of technologies and their data. Most importantly, it is in these stages of design that the knowledge produced is generative and has the potential to inform broader modes of thinking and future design practice [15].

The present work seeks to address these gaps in the context of a case study involving an ongoing design project tasked with developing LA tools for an early learning literacy game. Taking a co-design approach, we use the Inspiration Cards Workshop method (see [14]) to understand teachers' needs, desires and challenges to design and implement meaningful analytics for their practice. Our paper makes two contributions that inform LA designers, and more broadly designers of data-rich technologies. First, we propose Inspiration Cards Workshops as an effective methodology to involve practitioners with low experience with LA tool in the early stage of the design process, and we reflect on its limitations. Second, we propose three design principles that can guide the implementation of LA tools for primary school teachers, and we show how they can inform future design efforts.

\section{Background}

\subsection{The Role of Teachers in Learning Analytics Design}

One of the drivers behind the emergence of Learning Analytics 
(LA) tools for teaching and learning has been the growing recognition that learning with technology is most likely to occur with appropriate teaching and scaffolding [37]

Accordingly, it has been argued that the data provided through LA tools can raise teachers' awareness and reflection, informing their decision-making and consequent behaviours in the classroom [26][39][40]. LA tools typically allow the tracking of students' progress, the class' workflow and support class management [25]. Research on LA has chiefly focused on enhancing the effectiveness of teachers' orchestration of the classroom and its inevitable variability and complexity [6][31]. For example, MartinezMaldonado et al. [26] proposed a framework that captures, among other pedagogical aspects, four orchestration activities that may be supported by LA: design, adaptation, awareness and management.

Despite the pedagogical aspirations of such tools, however, the central role of data science in the context of LA has meant that researchers have often focused on the necessary algorithms involved in operationalizing LA as opposed to understanding the pedagogical needs that these algorithms should serve [1][6][15].

A recent design model seeking to address this gap is the LATUX workflow [25]. In developing LA tools for educational contexts Martinez-Maldonado et al. recognise the importance of "carrying out research to explore the new possibilities that learner data can offer for supporting instructors". The LATUX workflow describes how an iterative human-centred design process is instantiated in the case of LA. The model identifies an initial problem identification phase for LA, followed by a series of iterative formative evaluation stages.

However, albeit the recognition of the need for teachers' perspective, teacher input has tended to come later in the design process [1][8][15], for instance involving teachers to understand how existing LA tools can be effectively used (e.g. [8][27]) or gathering their feedback on existing LA tools, but rarely in defining the initial design agenda with them (c.f., [22][15][16]). LATUX, in particular, does not provide methodological guidance on how to support user involvement in the early generative design phase.

Recently, research in the LA field has started to explore the potential of design methods to meaningfully involve stakeholders, which we review next.

\subsection{Generative Design Techniques for Learning Analytics}

Considering the complexity of LA systems, previous research has identified barriers impeding stakeholders' meaningful contribution to the LA design process. For instance, Martinez-Maldonado et al. [24] and Mavrikis et al. [28] have shown that learners and teachers can have a limited understanding of data processing and visualisation techniques, and lack of data literacy impeding participation. In their work, they also provide rich case studies of LA design processes that involve users in frequent consultations and testing.
However, as Holstein et al. [16] pointed out, co-designing LA systems with stakeholders in an effective way requires generative design techniques that overcome possible barriers. In this and previous work Holstein et al. [15] described an early co-design approach with the aim to design a dashboard that answers real-time teachers' needs in the context of an intelligent-tutoring system (ITS). Overcoming concerns about data literacy, twelve K-12 teachers with 5 years of experience with ITS participated in a series of three workshops by addressing teachers' current needs, desires, and constraints.

However, very little research has provided a detailed account of codesign processes in the exploration and problem-definition phases. In addition to work by Holstein et al. [15][16], Prieto-Alvarez et al. [33] described their design thinking approach and co-design methods to involve learners in the early stages of the LA design process. Recent contributions have proposed cards as tool for codesigning LA tools. For instance, Prieto-Alvarez and colleagues have organised a workshop to propose their 'LA-DECK' set of cards as method to involve stakeholders in LA design and mean to unpack the design process [43]. Schmitz et al. have developed a board and cardgame that can be used in workshops to connect learning analytics and learning design, which can also act as tool for measuring teacher or student behaviour [44]. Other available examples focused on later design phases. For instance, Könings et al. [20] reported the use of co-design sessions to integrate student perspectives on current learning environments to improve the learning experience. With a similar goal, Cook-Sather [4] worked with undergraduate students and faculty members. However, the potential opportunities and limitations of these methods have not been explicitly discussed in the literature so far, particularly in relation to involving teachers in the important early generative phase.

The detailed case study illustrated next hopes to add to the emerging body of research in the LA field exploring how design thinking and methods allow to deeply involve stakeholders in the design of LA tools and other data-driven algorithmic systems.

\section{Methodology}

\subsection{Case Study}

"Navigo: the Pyramid of the Lost Words" is a reading game within which the player takes on the role of an archaeological adventurer, intent on unlocking the secrets hidden within an ancient and mysterious pyramid through completing learning activities focused on different areas of reading skill development. The game incorporates 16 different mini-game mechanics, which have been designed to develop reading skills across six language levels, namely Phonology, Morphology, Word Recognition, Orthography, Syntax and Morphosyntax. Each of the six language levels comprise of linguistic features that form part of a domain model of reading underlying the game. Within each pyramid room the player encounters a series of different mini-game activities which focus on a combination of reading skills targeted at the players' current 


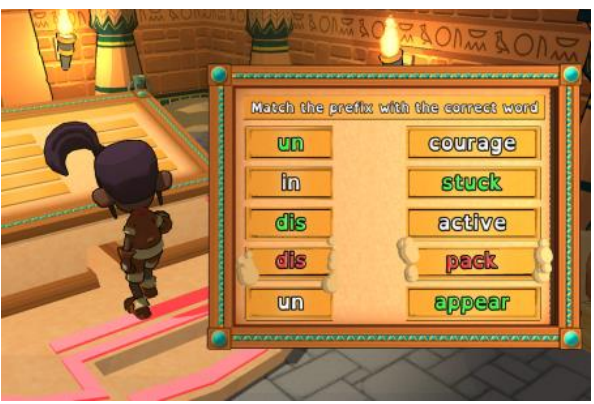

Figure 1a-Accuracy Game

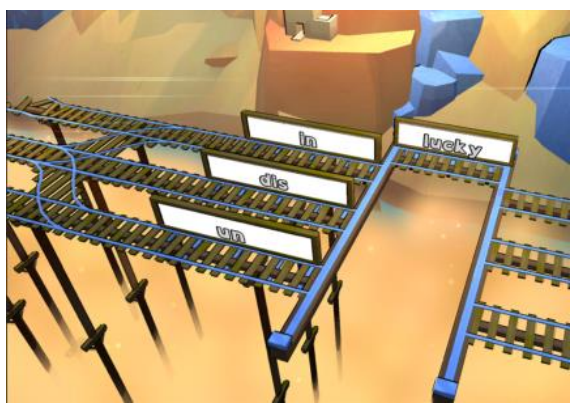

Figure 1b-Constructing Game

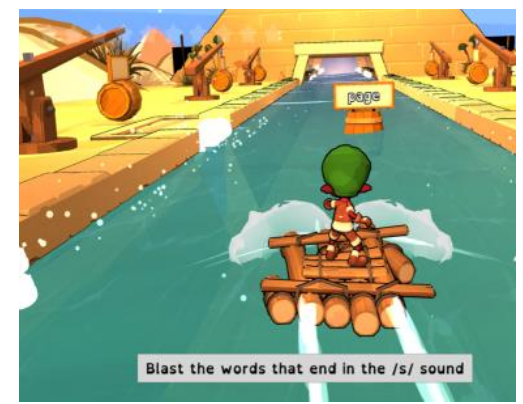

Figure 1c-Automaticity Game level in order to develop their reading fluency. Based on the reading development literature, the 16 mini-game mechanics were designed to represent three types of activities:

Accuracy mini-games develop declarative knowledge through focusing on an individual language feature and rule (e.g. see Fig. 1a);

Constructing mini-games develop declarative/procedural knowledge through applying multiple linguistic rules in context (e.g. see Fig. 1b);

Automaticity mini-games develop atomisation through timed reading practice (e.g. see Fig. 1c).

For each linguistic feature they encounter, children progress between these three stages of reading by playing different game mechanics to achieve the goal of fluency for that feature.

\subsection{Participants}

Given our application of LA to the domain of literacy, and reading specifically, we sought to involve practitioners from different contexts who were supporting students with diverse literacy needs. Potential participants included primary school teachers, special education needs (SEN) teachers and SEN coordinators. Advertising the study widely through our existing school and professional networks, three different sessions were arranged.

In all three sessions participation was voluntary and all of the participants provided informed consent. Besides the practitionerparticipants, each of the sessions additionally included two researcher-participants, one with expertise in literacy and the NaviGo games, and one researcher with knowledge of LA.

Session 1 (4 practitioner-participants): participants were four SEN and personalised learning experts, i.e., two ex-teachers who now delivered professional teacher training for dyslexia, one teacherstudent participating in the dyslexia training and one speechlanguage therapist;

Session 2 (2 practitioner-participants): participants included a teacher working on literacy in Year 2, and the head-teacher who had a literacy background and taught literacy sessions occasionally. These two literacy practitioners were based in a school with a strong track record in supporting students who struggled with literacy;

Session 3 (4 practitioner-participants): participants comprised a Year 1 literacy teacher, a Year 2 teaching assistant, a Year 3 teacher and the deputy head-teacher who was also the SEN coordinator. These practitioners were based in a school adopting holistic approaches to literacy through developing their own curriculum.

\subsection{Participatory Design Workshops}

We facilitated three PD workshops of around 1h15mins each, which were structured around three phases informed by Hornecker et al. [18].

\subsubsection{Phase 1: Exploring existing practices}

In facilitating a transition from current practice to new opportunities we started each session with a group discussion on participants' current data practices at school. Given their current training role, participants of session 1 were encouraged to draw on their past professional experiences with data. This phase aimed to generate a shared understanding between participants and researchers about (i) the nature of current data practices; (ii) how data are currently collected; (iii) the impact of those data on participants' teaching practices.

\subsubsection{Phase 2: Familiarization with technology}

The second phase aimed to introduce the NaviGo games, and support teachers' understanding of the domain model of literacy employed and the pedagogy that guided the game design (see Section 3). In particular, we selected three games from the three types of reading activities. First, we introduced each game type through a visual representation explaining the learning activity, instruction type, learning objective, game distractors and feedback information. We then asked participants to play each of the three games, whilst referring to the visual representation in order to link the pedagogical rationale with the game play experience. 


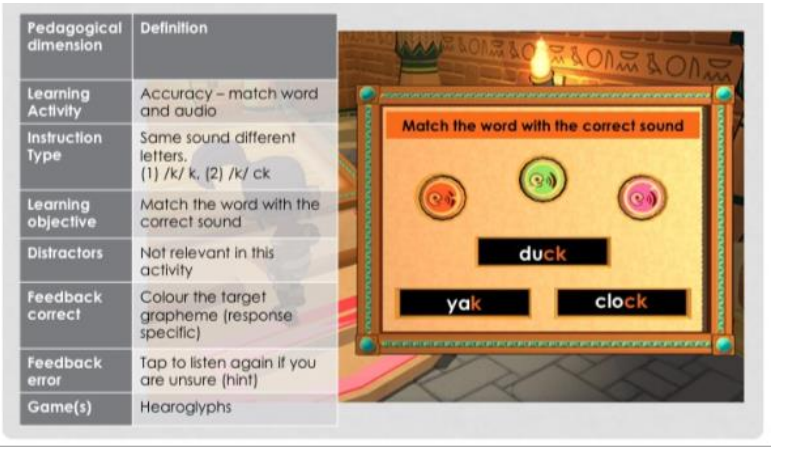

Figure 2. A visual representation used to describe the pedagogical design of an accuracy game called 'Hearoglyphs'

\subsubsection{Phase 3: Exploring new possibilities}

The last part of the workshops aimed to support the identification of inquiries teachers wanted to pursue with the data produced by the NaviGo game. We prompted participants to generate new

questions that could be answered with game data, to share with us the rationale of these questions, and how the answers obtained through the data would inform their teaching. We used these

prompts to elicit teachers' critical engagement with data and the possibilities it introduces.

By probing the 'whys' of particular pedagogical data uses, we faced the challenge of supporting teachers' understanding of a potentially complex design space characterized by different reading phases, learning outcomes, possible data, and so on. The Inspiration Card Workshop method developed by Halskov and Dalsgård was employed to address both requirements. In particular, we were drawn to this method because of its tangible and material form, and its potential to scaffold conversations that were closely coupled with what technology could achieve. An Inspiration Card is an index card presenting a space for a title, image and description. In combining two categories of cards, Technology Cards and Domain Cards, it is possible to uncover generative opportunities for technology design. While Inspiration Cards were conceived as a generative method, the original authors of this method explain that participants' prior knowledge, experience, and practices shape the outcomes of the workshop [14] in turn leading to different forms of transcendence.

Constructing the cards: Our first step was to design the cards. A Technology Card presents a specific technology or an application of one or more technologies. Given our focus, we designed the Technology Cards showcasing aspects of the NaviGo games and LA, namely the properties of the game activities (see Fig. 4, column 1), the possible game log data that could be captured (column 2 and 3) and the different possibilities for representing them graphically (column 4). Next, following Halskov and Dalsgård's guidance, we recruited the support of two experts in literacy learning (both of whom also participated in Session 1) and collaboratively we created the Domain Cards. Domain cards represent important domain information such as relevant practices, or people and their 4 characteristics. Our Domain Cards included the learning objectives relevant to the reading domain (column 5), the profiles of different students (column 6) and their classroom configurations (column 7), and finally the teaching methods used in literacy (column 8). Figure 3 captures the 30 cards designed.

Compared with Halskov and Dalsgård [14] whose cards were more ambiguous and open to interpretation, the existence of the NaviGo games meant that our cards showed specific aspects of the technology and its potential context of use. Despite this difference, we believed that the novelty of the LA technology, as well as the multiple data opportunities it introduced in the context of our participants' experience, would foster clear generative opportunities. Furthermore, we encouraged participants' proposals and different visions on LA possibilities by repeatedly reminding them of the possibility to create and use new cards whenever needed as suggested by Halskov and Dalsgård [14]Error! Reference source not found.

Using the cards: Having designed the cards, we proceeded to run the three participatory design workshops in line with guidance reported in [14]. During each workshop, we displayed all of the cards on the table one by one, while describing their meaning and answering possible questions raised by participants. This allowed researchers and participants to negotiate a shared interpretation of each card. Following the introduction of the cards, we invited participants to combine them in order to co-construct pedagogical scenarios. In total this generated 14 new scenarios across the three workshops. Figure 3 shows a combination of cards that formed a scenario in one of the sessions where the teachers involved envisioned collecting data at a whole class level to inform the later organisation of smaller groups.

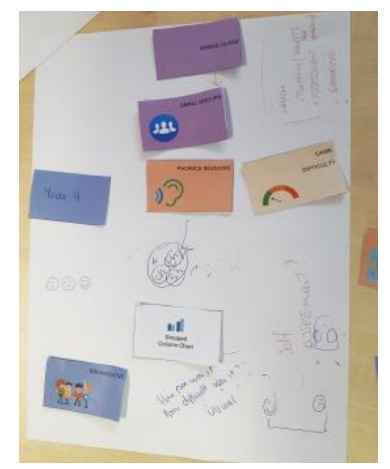

Figure 3. A scenario constructed with the cards

\subsection{Data Collection and Analysis}

Each of the three workshops was video recorded totaling 3.45 hours of video data. We used the inqScribe software to analyse the videos. Following Derry et al. [5], each video was broken down into segments representing each scenario envisioned through the new data-driven inquiries proposed. Next, thematic analysis was employed to shed light on the ways in which scenarios were constructed using the cards. In particular, we followed the 6 step method proposed by Braun and Clarke [3]: (i) we watched the video 


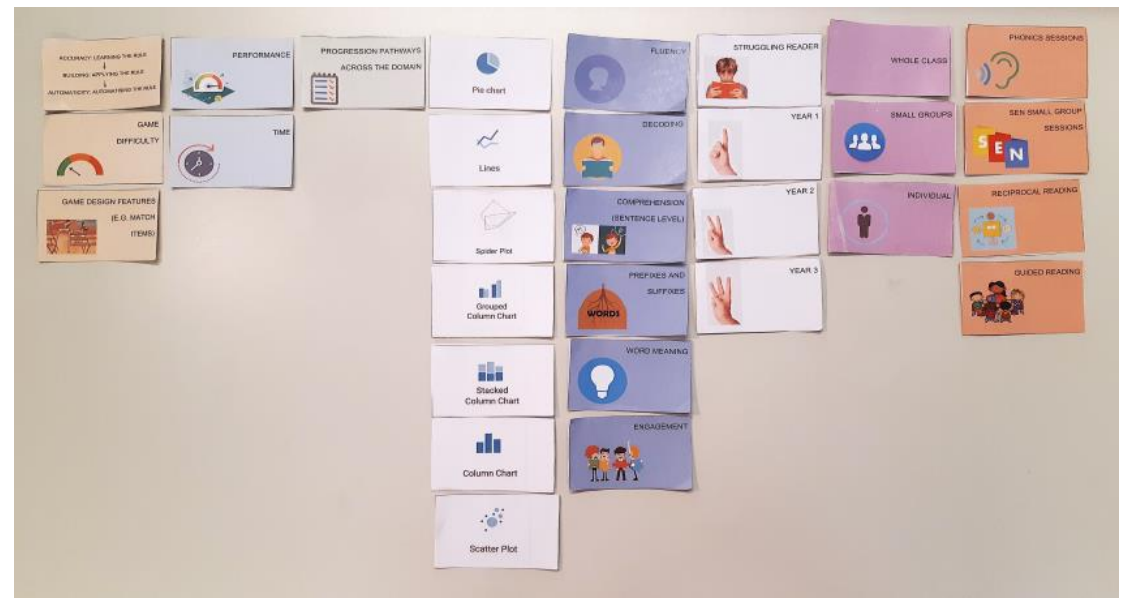

Figure 4. Technology Cards (columns 1-4) and Domain Cards (columns 5-8)

recordings multiple times, transcribing part of the data to note down initial ideas; (ii) coded the entire dataset systematically in a 'datadriven' way; (iii) collated an initial 24 coding categories into 8 themes; (iv) reviewed the themes iteratively, discussing possible biases in the interpretation, checking their expression of the full dataset; (v) refined the specifics and details for each theme, their title and the overall narrative of the analysis; (vi) selected meaningful extracts, relating back to the research question, literature and analysis. Through this process we generated eight categories which capture teachers' needs, desires and challenges at different levels. During the analysis, we also wrote down how participants used the cards in each scenario. The notes supported the methodological reflections described in the discussion section.

\section{Findings}

\section{Negative Experiences with Educational Technologies}

Similar to Holstein et al. [15] whose teacher participants identified that their students sometimes lacked genuine engagement with technology, our teachers explained that the interactivity of digital activities could mask children's lack of strategic engagement in their learning. In session 2, the head teacher explained that her school assessed literacy through STAR, a digital system based on multiple choice assessment methods. While this was beneficial for centralising data to monitor student progress, it also led to trial and error approaches: "A lot of children were guessing (the correct response) and there was to no way to know where they were guessing $[\ldots]$ They just sit there tapping around until they get some results.”

Whereas to show a holistic view of a student's learning LA must collect data through continuous practice over a breadth of activities, the lack of control over how children independently engaged with digital learning activities led to a lack of trust in the technology. In turn, this prompted teachers to propose pedagogies that relied on bounded learning activities they themselves controlled, consequently impacting on the scope of data collected for use and further inference by the LA. As the head teacher in session 2 suggested "...it might be that the game (automatically) creates the learning pathway and then the teacher works on where they (the students) are with the game before you play that game. Because sometimes it is just play and play and play... and it is an assumption that... they are learning..."

\section{Extrinsic Professional Demands Shaping Engagements with Data}

Supporting past research that shows teacher expectations and effective use of LA are shaped by extrinsic factors [7][22][27], teachers contextualized LA in the problems associated with the profession of teaching, and in particular the limited time and increased workload issues they faced. LA were therefore seen to ameliorate these problems by suggesting pedagogical actions that would have the highest impact, either by affecting the most students or those students who were at the highest risk.

While defining how to graphically represent students' difficulties with word decoding during session 3 , all of the participants agreed on the importance of gaining insights on trends within the class given their lack of time to engage with individual students. The deputy head teacher pointed out "Honestly, it (the LA visualisation) should be small groups of individuals, trends rather than whole class because we know ourselves that time is such a premium already..." This lack of time to engage with individual student data emerged during three occasions across the two other sessions, with participants suggesting a focus on data with a low level of detail, for example showing students' performance on curriculum learning objectives allowing them to make swift connections with existing modes of teaching.

Moreover, teachers' time limitations did not only shape what data they wanted from LA, but also how it would be delivered. Instead of them spending time querying the data, teachers wanted the technology to send them notifications to save time. For example, the teacher in session 2, sought both key classroom trends that would support planning at a class level, and data about students at risk. Sound and pushing information were key to drawing her attention to these insights: "it would be good to have like 'ting ting 
ting' $50 \%$ of students are struggling with the prefixes, so that I know that I need to work on the prefixes... Like a notification to the teacher saying 'well this child is struggling' and then maybe you go there and figure it out!"

\section{Students' Learning}

Across all sessions, participants explained that children in the UK faced repeated literacy assessments and many found it particularly stressful when undergoing these. In contrast to this current situation, in session 1 it was suggested that technology could play an unobtrusive and critical role in accelerating the diagnostic identification of potential struggling readers. Moreover, the potential of data to support precision of such diagnosis prompted one teacher to foresee the opportunities for individualised support whereby quality teaching might proceed game play and practice: "...Performance on some items. For example, we can see which prefixes they struggle with, exactly. Which are the known ones and which are not. [...] And maybe we can link this to the time. [...] If it is about which suffixes and prefixes you can have like charts like group column charts. And in this case you can have a thing called precision teaching? Target the items from the outside while they progress with the game."

Alongside the problem of diagnosing struggling readers, two participants reflected on the profile of struggling readers and their existing challenges with engagement and concentration. For example, during session 1, one of the teachers described how students who struggle with literacy must work intensively and persistently to gain fluency, a process that inevitably impacts the facilitative positive role of engagement in learning. As a consequence, she expressed an interest in using LA to ask "how long do they play (the game), to know about their concentration and engagement".

\section{Constructing Evidence-Based Small Group Sessions}

In all of the sessions, our participants described their use of small groups as an effective method of teaching, and one that allowed them to provide differentiated planning or support. Students' collaborative work was usually organised according to students' levels of ability [23], with the teacher acting as facilitator and orchestrator of the different groups. LA were viewed as an evidenced-based approach to organise and update these small groups, a classroom activity also recognised in MartinezMaldonado et al.'s pedagogical phases of 'management' and 'planning' [26]. As two of the participants in session 2 explained, LA can help to divide students according to their abilities, allowing for the planning of learning activities informed by the data: "maybe if it can generate reports on ability groups..." (...) "it would be interesting to know which are the strands, so that you know how they perform for each strands, in order to organise the groups better". More broadly, this finding also confirms the pedagogical significance of previous research that focused on the design and development of digital tools to promote better similarity-based grouping in the classroom [29].

\section{Enhancing individualized interventions}

Individualized interventions target specific students' learning needs with the aim to overcome the identified gaps through systematic, one-to-one teaching sessions [12]. Across all sessions, our participants recognised the value of this teaching method to improve specific aspects of reading a student may struggle with.

The speech therapist in session 1 imagined the possibility to diagnose a student's learning gaps through standardised tests first and then use the games to 'teach' these skills, and assess students' reading progress through the opportunities offered by LA: "you might want to do some standardised tests first that help you to decide what kind of areas you want to focus on... Some kind of diagnosis before and then target the intervention with NaviGo to train the skills. To master decoding then prefixes and suffixes then comprehension." Similarly, the teacher in session 2 proposed a scenario in which a struggling reader uses the games as an intervention, with the teacher monitoring the effects of the game on learning through the LA tools: "So, you have an individual, problem with decoding. This is an intervention and you want to measure how their decoding improves over time?".

Therefore, teachers naturally transposed the intervention model of high quality teaching onto digital technology. With games delivering an intervention aiming to support students with a familial risk of dyslexia, LA was considered to be an assessment tool used to monitor responsiveness, aligning with the design of similar technologies such as GraphoGame [34], whilst also supporting the potential of LA for assessment [10].

\section{Enhancing Reciprocal Reading}

Reciprocal reading methods aim to improve reading comprehension through students working together as a group on the same text. Typically, each student is assigned to a set of tasks related to the strategies of predicting, classifying, questioning and summarising the meaning, with these strategies rotating within each group [38]. During two occasions teachers identified the opportunity of technology to reinforce this teaching method, with LA monitoring if students' comprehension improves as a result of reciprocal reading. For example, one participant imagined how this could fit into her current teaching process, describing the potential of the games and data to monitor and provide evidence-based awareness on the outcomes of the reciprocal reading sessions: "the comprehension stuff is about reading in groups... It would be nice to see how they score in the games and then they go in rotation in the (reciprocal reading) groups and then they go again in the games... to see if they do better. Something they do every week. And it would be nice to have a report on comprehension over time to see if they improve?".

\section{Enhancing teachers' self-assessment}

In contrast to the theme above where teachers sought to evaluate a particular teaching method, our participants also identified LA as a mechanism through which to obtain feedback on their practices. In session 1, this possibility to enhance teachers' self-assessment in a data-driven way emerged twice. For example, one participant proposed to use the games after a teaching session to understand its 
Table 1. Example teacher ideas.

\begin{tabular}{|c|c|c|}
\hline What & Why & Pedagogical aim \\
\hline $\begin{array}{l}\text { Knowledge of percentage of students } \\
\text { struggling to achieve a learning objective }\end{array}$ & $\begin{array}{l}\text { Teachers lack the time to explore individual } \\
\text { student learning }\end{array}$ & $\begin{array}{l}\text { Plan learning activities addressing } \\
\text { the most common gaps in class }\end{array}$ \\
\hline $\begin{array}{c}\text { Representation of learning trends within } \\
\text { the class }\end{array}$ & $\begin{array}{l}\text { To have a class overview without consulting } \\
\text { individual student performance }\end{array}$ & $\begin{array}{l}\text { To decide when to move to the next } \\
\text { learning objective at a class level }\end{array}$ \\
\hline $\begin{array}{c}\text { Identification of a student who is } \\
\text { particularly struggling and the specific } \\
\text { weakness }\end{array}$ & $\begin{array}{l}\text { To speed up the time-consuming and } \\
\text { stressful identification of struggling readers }\end{array}$ & To plan individualised support \\
\hline $\begin{array}{c}\text { Insights on how long struggling readers } \\
\text { play }\end{array}$ & $\begin{array}{l}\text { The intense work on fluency can impact } \\
\text { students' concentration and engagement }\end{array}$ & $\begin{array}{c}\text { To identify lack of student } \\
\text { concentration and engagement }\end{array}$ \\
\hline Reports for ability groups & $\begin{array}{c}\text { To know what are the strands within the } \\
\text { class }\end{array}$ & $\begin{array}{l}\text { To organise the group sessions } \\
\text { better }\end{array}$ \\
\hline $\begin{array}{l}\text { Insights of the effects of the teaching } \\
\text { methods used on students' learning }\end{array}$ & $\begin{array}{l}\text { To reflect on the learning design and } \\
\text { methods used with students }\end{array}$ & $\begin{array}{l}\text { Teaching self-assessment and } \\
\text { planning of future activities }\end{array}$ \\
\hline $\begin{array}{l}\text { Impact of work on a particular learning } \\
\text { objective on the others }\end{array}$ & $\begin{array}{c}\text { To know the effects of previous learning } \\
\text { design involving work on a learning } \\
\text { objective on others }\end{array}$ & Teaching self-assessment \\
\hline $\begin{array}{l}\text { Struggling readers' progress against } \\
\text { themselves on a learning objective }\end{array}$ & $\begin{array}{c}\text { To know about struggling readers' strengths } \\
\text { and learning achievements }\end{array}$ & $\begin{array}{l}\text { To assess struggling readers' } \\
\text { strengths and improvements }\end{array}$ \\
\hline Time spent to complete a familiar game & $\begin{array}{l}\text { To re-challenge students on previous } \\
\text { learning objectives they are confident with }\end{array}$ & $\begin{array}{l}\text { To enhance students' motivation } \\
\text { and reinforce their learning }\end{array}$ \\
\hline $\begin{array}{l}\text { Time spent to complete a new game on a } \\
\text { more advanced learning objective }\end{array}$ & $\begin{array}{l}\text { To engage students individually or in } \\
\text { competitions on future learning contents }\end{array}$ & $\begin{array}{c}\text { To promote students' engagement } \\
\text { and assess their performance on } \\
\text { new tasks }\end{array}$ \\
\hline
\end{tabular}

effects on students' learning, and then plan the following activities accordingly: "you can use NaviGo at the end of a session to assess your teaching... You use the learning analytics to inform what you did and then to structure the following activities". This finding is similar to Holstein whose teachers asked for evidence-based insights on the effects of their own teaching on students' learning [15].

$L A$ raising the visibility of existing engagements and achievements Previous research has shown there is a strong correlation between engagement and learning (e.g. [21]), suggesting that promoting students' engagement generates a positive impact on their persistence in learning and learning outcomes. Embracing this view as part of their pedagogy, during session 3, teachers repeatedly identified engagement as the main goal of any pedagogical scenario. The digital data of learning outcomes captured in LA was broadly interpreted as a consequence of engagement, raising its visibility and thus reinforcing the school culture. It is in this spirit that teachers strategically proposed activities for game play in which the data captured within LA would raise the visibility of achievements students had previously evidenced. Teachers envisioned the use of the NaviGo games at the end of the year, to re-challenge children on what they learnt in the previous months as well as a warm-up for September. One of the teachers proposed engaging students in competitions against themselves, or in pairs, on familiar learning tasks collecting data on the time they spent to finish a game.

Within the above examples teachers approached the LA as an end in itself. However, when discussing the potential of LA for
Recent work has recognised the importance of enabling configurability of LA tools for teachers. For instance, Mavrikis et al. [30] reflected on their LA design process for exploratory learning environments and discussed the need to allow teacher's configuration to accommodate different preferences. Similarly, Wise and Vytasek [42] proposed a 'principle of customisation' when implementing LA tools. As noticed by Rodríguez-Triana et al. [35] allowing teacher's decision-making can lead to an increased sense of agency and control.

This double-faced need was interpreted in interface and visualizations graphically structured but open to teachers' choices in terms of quantity of learners (one student vs. class or group) and learning objectives. Figure 6 and 7 show the two different 'views' available in the NaviGo analytics, and the possibility to easily switch between the two. The interface offers the possibility to select the granularity of learning objective, allowing to answer specific questions over a period of time and targeted to specific parts of the domain.

Designing for Teacher's Action and Control

As shown in Table 1 and in the Findings section more broadly, teachers' ideas were oriented toward precise pedagogical aims. Our participants described the importance of obtaining actionable insights mined from data that can be translated into concrete teaching plans and choices. This confirms previous research orienting LA design toward teacher's action and reflection [24][39][40]. However, we also identified a variety of possible actions deriving from the same insight e.g. representations of the student learning level (Fig. 5). Considering these findings, we 


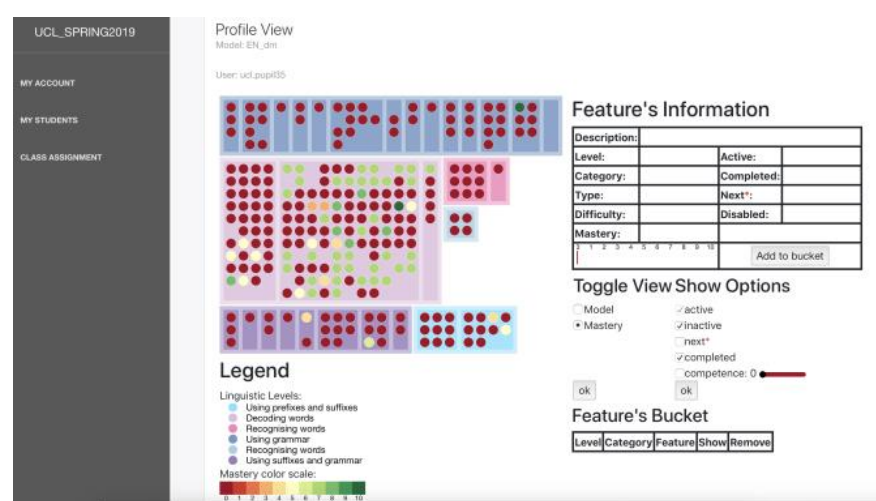

Figure 5. Dashboard prototype: Individual student view

intentionally chose not to suggest specific actions and instead to promote teacher's control over pedagogical plans and intentions. In line with a view on intelligent technologies as support for teaching, the NaviGo dashboard represents students' mastery in a language domain that is aligned with the curriculum but open to different pedagogical usages. Indeed, these insights might inform different planning and assessment activities as well as teacher reflection, allowing the design and re-design of activities and eventually professional development.

\section{Designing for Visible Learning}

Our findings have highlighted the importance of giving visibility to students' gaps, progress and achievements in learning. Participants described that detailed and evidence-based insights on their students' learning could augment effective teaching methods for literacy, such as individualized interventions and grouping. Furthermore, we identified how fine-grain traces and representations of students' learning could support the identification of struggling readers in an unobtrusive way.

These insights support a view on LA as a way to enhance, add precision and improve existing learning design practices. By putting teachers' learning design practices at the centre of our LA design moves the discourse toward a more meaningful alignment between LA and learning design [36][2].

In our LA prototype, we provide evidence-based insights on students' 'mastery' for each language feature using colours and grades to provide detailed information on the student learning level. Figure shows a preview for individual students.

\section{Discussion}

Our research supports new methodological reflections on how to engage in co-design with novice technology users. Previous work in the field of LA has argued in favour of involving teachers in the initial stages of the design process, for example through a 'problem identification' stage [24]. However, there has been limited methodological development to determine how this is achieved [16][32], especially with groups that lack the data literacy background or are not used to employ learning analytics in their everyday teaching. The present study employed co-design

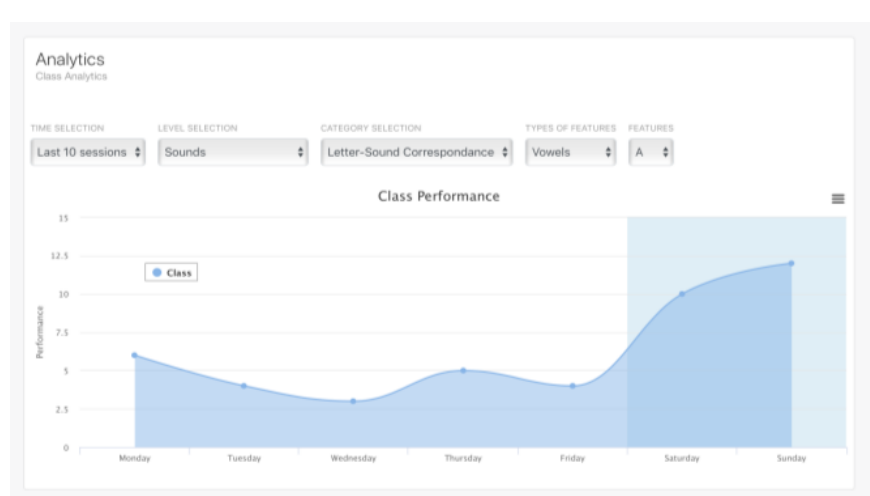

Figure 6. Dashboard prototype: Class view

methods, in part because of our commitment to reflexively engage practitioners with low experience with LA tools in the early generative stage of the design process.

Inspiration Cards Workshops as effective method to involve practitioners in co-designing LA

Previous research has identified barriers that impede stakeholders' meaningful contribution to the LA design process [24][28], such as limited data literacy or lack of data processing and visualization understanding. Conversely, in our study, despite our participants' lack of experience with LA or other data-rich technologies, they were quick to understand how to use the Inspiration Cards and to imagine new scenarios. Despite us taking a more directive role to scaffold their first scenario construction, in most cases teachers reached out for the cards and independently created their first scenario.

Different workshop characteristics promoted participation. First, we scaffolded the activities around the use of visual tangibles. In contrast to the abstract and complex nature of algorithmic systems, we argue that the physicality and practical structure of the task promoted understanding and subsequent active participation of non-technical practitioners. With the aim to support participation further, we designed two categories of cards (Technology Cards and Domain Cards) to connect unfamiliar data opportunities to learning design practices that are well-known and part of the everyday life of our participants. As discussed in the background section (see section 2.2.), to the best of our knowledge, this is the first contribution that describes how cards can be used in workshops to involve practitioners in LA design.

We reinforced our methodological choices with targeted support to each group of participants during the workshop. In each session, one researcher with experience in design and one researcher with understanding of LA collaboratively promoted participants' imagination by asking questions, while also bounding the conversation around what was technologically feasible. Last but not least, the collaborative nature of the sessions allowed rich discussions that led to a shared creation of ideas, also thanks to the mixed composition of the three groups. For instance, the presence of head-teachers as well as teaching assistants allowed to capture 
pedagogical as well as institutional-political perspectives within the same educational infrastructure.

\section{Methodological Trade-offs}

By situating the design of LA in an already developed technology, the NaviGo games, possibilities for new alternatives were bounded by the design of the game activities and their domain. The specificity of cards provided a scaffold for the construction of very particular technology scenarios that were closely coupled with the NaviGo games. This close coupling meant that teachers exercised more control over the final design outcome.

Alongside these methodological strengths, however, the boundaries our process created may have invited particular perspectives, e.g. enhancements to current teaching methods represented within the cards. In fact, our participants rarely stepped back to question the assumptions embedded within the cards, nor did they create new cards. Similarly, teachers did not reflect on their own relationship with technology as was reported in Holstein's et al. work with expert teachers [15]. For instance, all of our participants assumed a sense of control over the teaching process and uncritically adopted a sense of trust that data would improve specific aspects of it. Our findings therefore suggest a possible methodological trade-off. The same methodological constraints that facilitate participation and power in the design process, may also limit teachers' criticality.

\section{Design Principles for LA tools for teachers}

Starting from co-design insights, we developed three broad design principles - Designing for Configurability, Designing for a Variety of Actions and Designing for Visible Learning - that can guide implementation of LA tools for primary school practitioners.

We abstracted the principles from our findings. For instance, one of the strongest findings beyond Designing for Configurability is the contextual and situated nature of participants' needs and desires, and the necessity to allow teacher appropriation [8]. Instead of treating our findings as requirements, we formulated a broad principle that different LA designers can actualize in different ways. This way future co-design sessions with primary education practitioners can enrich and refine our initial set of principles.

Our case study provides a first example of principles interpretation and implementation. In unveiling our LA, interface and visualization design choices we hope to provide methodological guidance for other researchers interested in taking a designoriented, human-centred perspective with LA and other algorithmic systems.

\section{Conclusion}

Misrepresentation of teachers' needs, desires and challenges in LA design is a problem that can affect adoption (e.g. [11]). Co-design methods allow to give voice to education stakeholders, and involve them meaningfully in the design journey [33]. This paper provides a detailed case study describing a co-design approach to LA design in the context of an existing learning game. By reflecting on our design choices from co-design workshops with end-users to dashboard prototype we provide methodological guidance to other LA researchers interested in taking a human-centred approach to LA design. Our contribution is two-fold. First, we propose Inspiration Cards Workshops as effective methodology to involve practitioners with low experience with LA tool in the early stage of the design process, and we reflect on opportunities and limitations. Second, we propose three design principles that can guide the implementation of LA tools for primary school teachers that we think go beyond language games apps, and we show how they can inform future design efforts.

\section{ACKNOWLEDGEMENTS}

[Blank]

\section{REFERENCES}

[1] Ryan S. Baker. 2016. Stupid tutoring systems, intelligent humans. International Journal of Artificial Intelligence in Education, 26 (2): 600614. https://doi.org/10.1007/s40593-016-0105-0

[2] Annesha Bakharia, Linda Corrin, Paula de Barba, Gregor Kennedy, Dragan Gasević, Raoul Mulder, David Williams, Shane Dawson, Lori Lockyer. 2016. A conceptual framework linking learning design with learning analytics. 2016. In Proceedings of the 6th International Conference on Learning Analytics and Knowledge, 329-338.

[3] Virginia Braun and Victoria Clarke. 2006. Using thematic analysis in psychology. Qualitative Research in Psychology, 3 (2). 77-101. https://doi.org/10.1191/1478088706qp063oa

[4] Alison Cook-Sather. 2014. Multiplying perspectives and improving practice: what can happen when undergraduate students collaborate with college faculty to explore teaching and learning. Instructional Science 42 , 1, 31-46. http://dx.doi.org/10.1007/s11251-013-9292-3.

[5] Sharon J. Derry, Roy D. Pea, Brigid Barron, Randi A. Engle, Frederick Erickson, Ricki Goldman, Rogers Hall, Timothy Koschmann, Jay L. Lemke, Miriam Gamoran Sherin and Bruce L. Sherin. 2010. Conducting Video Research in the Learning Sciences: Guidance on Selection, Analysis, Technology, and Ethics. Journal of the Learning Sciences, 19 (1): 3-53. https://doi.org/10.1080/10508400903452884

[6] Pierre Dillenbourg and Patrick Jermann. 2010. Technology for classroom orchestration. In K.M. and S.I. (eds.) New Science of Learning, Springer New York, 525-552. https://doi.org/10.1007/978-1-4419-5716-0_26

[7] Pierre Dillenbourg, Guillaume Zufferey, Hamed Alavi, Patrick Jermann, Son Do-Lenh, Quentin Bonnard, Sébastien Cuendet and Frédéric Kaplan. 2011. Classroom Orchestration: The Third Cycle of Usability. In Proceedings of the 11 th Conference of Computer-Supported Collaborative Learning, 1, 510-517. Retrieved September 18th, 2019 from https://pdfs.semanticscholar.org/da46/4cf0f96d8a5dcb35c55c198fdbe83f aafe6 bpdf

[8] Alan Dix. 2007. Designing for Appropriation. Proceedings of the 21 st BCS HCI Group Conference. https://doi.org/10.1145/3170358.3170372.

[9] Mollie Dollinger and Jason M. Lodge. 2018. Co-creation strategies for learning analytics. In Proceedings of the 8th International Conference on Learning Analytics and Knowledge - LAK '18, 97-101. https://doi.org/10.1145/3170358.3170372

[10] Cath Ellis. 2013. Broadening the scope and increasing the usefulness of learning analytics: The case for assessment analytics. British Journal of Educational Technology, 44 (4): 662-664. https://doi.org/10.1111/bjet.1202

[11] Dragan Gâsević, Shane Dawson, Tim Rogers, Danijela Gasevic. 2016. Learning analytics should not promote one size fits all: The effects of instructional conditions in predicting academic success. The Internet and Higher Education 28, 68-84. https://doi.org/10.1016/j.iheduc.2015.10.002

[12] Yvonne Griffiths and Morag Stuart. 2013. Reviewing evidence-based practice for pupils with dyslexia and literacy difficulties. Journal of Research in Reading, 36 (1): 96-116. https://doi.org/10.1111/j.G.1R46IF7F9IT8H17S7.2a0n1d1S.0T1U4A95R.Tx

[13] Sergio Gutierrez-Santos, Manolis Mavrikis, Eirini Geraniou and Alexandra Poulovassilis. 2017. Similarity-based grouping to Support Teachers on Collaborative Activities in Exploratory Learning 
Environments. IEEE Transactions on Emerging Topics in Computing 5(1). 56-68. https://doi.org/10.1109/tetc.2016.2533318

[14] Kim Halskov and Peter Dalsgärd. 2006. Inspiration Card Workshops. In Proceedings of the $6_{\text {th }}$ ACM Conference in Designing Interactive Systems (DIS'06), 2-11.https://doi.org/10.1145/1142405.1142409

[15] Kenneth Holstein, Bruce M. McLaren and Vincent Aleven. 2017. Intelligent tutors as teachers' aides. In Proceedings of the Seventh International Learning Analytics \& Knowledge Conference on - LAK '17, 257-266. https://doi.org/10.1145/3027385.3027451

[16] Kenneth Holstein, Bruce M. McLaren and Vincent Aleven. 2019. Codesigning a real-time classroom orchestration tool to support teacher-AI complementarity. Journal of Learning Analytics 6, 2, 27-52. http://dx.doi.org/10.18608/jla.201962.3

[17] Kristina Höök and Jonas Löwgren. 2012. Strong concepts: Intermediatelevel knowledge in interaction design research. ACM Transactions in Human-Computer Interaction, https://doi.org/10.1145/2362364.236237

[18] Eva Hornecker, John Halloran, Geraldine Fitzpatrick, Mark Weal, David Millard, Danius Michaelides, Don Cruickshank and David De Roure. 2006. UbiComp in Opportunity Spaces: Challenges for Participatory Design. In Proceedings of the $9_{\text {th }}$ Conference in Participatory Design, Trento, Italy, 47-56. https://doi.org/10.1145/1147261.1147269

[19] Adrian Kirkwood and Linda Price. 2013. Technology-enhanced learning and teaching in higher education: what is 'enhanced' and how do we know? A critical literature review. Learning, Media and Technology, 39 (1): 6-36. https://10.1080/17439884.2013.770404

[20] Karen D. Könings, Tina Seidel, Jeroen J.G. van Marriëboer. 2014 Participatory design of learning environments: integrating perspectives of students, teachers, and designers. Instructional Science 42, 1, 1-9.

[21] Jung-Sok Lee. 2014. The Relationship Between Student Engagement and Academic Performance: Is It a Myth or Reality? The Journal of Educational $\quad$ Research, $107 \quad$ (3): https://doi.org/101080/00220671.2013.807491

22] Amna Liaqat, Benett Axtell, Cosmin Munteanu and Carrie Demmans Epp. 2018. Contextual Inquiry, Participatory Design, and Learning Analytics: An Example. In Proceedings of the LAK 2018 Workshop on Participatory Design and Learning Analytics.

[23] Yiping Lou, Philip C. Abrami, John C. Spence, Catherine Poulsen, Bette Chambers and Sylvia d'Apollonia. 1996. Within-Class Grouping: A MetaAnalysis. Review of Educational Research, 66 (4): 423-458. https://doi.org/103102/00346543066004423

[24] Roberto Martinez-Maldonado. 2016. Seeing Learning Analytics Tools as Orchestration Technologies: Towards Supporting Learning Activities across Physical and Digital Spaces. In CEUR Workshop Proceedings, 7073.

[25] Roberto Martinez-Maldonado, Abelardo Pardo, Negin Mirriahi, Kalina Yacef, Judy Kay and Andrew Clayphan. 2015. The LATUX workflow. In Proceedings of the Fifth International Conference on Learning Analytics And Knowledge - $\quad$ LAK $\quad 15, \quad 1-10$. https://doi.org/10.1145/2723576.2723583

[26] Roberto Martinez-Maldonaldo, Simon Buckingham-Shum, Bertrand Schneider, Sven Charleer, Joris Klerkx and Erik Duval. 2017. Learning Analytics for Natural User Interfaces. Journal of Learning Analytics, 4 (1). 24-57. https://doi.org/10.18608/jla.2017.41.4

[27] C. Matuk, L. Gerard, J. Lim-Breitbart and M.C. Linn. 2016. Teachers' reflections on the uses of real-time data in their instruction Poster session presented at AERA 2016, Washington, DC, USA.

28] Manolis Mavrikis, Sergio Gutierrez-Santos, Eirini Geraniou, Celia Hoyles, George Magoulas, Richard Noss and Alex Poulovassilis. 2013. Iterative context engineering to inform the design of intelligent exploratory learning environments for the classroom in al., R.L. ed. Handbook of Design in Educational Technology, Routledge, 80-92.

[29] Manolis Mavrikis, Sergio Gutierrez-Santos and Alex Poulovassilis. 2016. Design and Evaluation of Teacher Assistance Tools for Exploratory Learning Environments. In Proceedings of the Sixth International Conference on Learning Analytics \& Knowledge, 168-172. https://doi.org/10.1145/2883851.2883909

[30] Manolis Mavrikis, Eirini Geraniou, Sergio Gutierrez-Santos and Alex Poulovassilis. 2019. Intelligent analysis and data visualisation for teacher assistance tools: The case of exploratory learning. British Journal of Educational Technology. https://doi.org/10111/bjet.1276

[31] Luis P. Prieto, Martina Holenko Dlab, Israel Gutiérrez, Mahmoud Abdulwahed and Walid Balid. 2011. Orchestrating technology enhanced learning: a literature review and conceptual framework. Int. J. Technology Enhanced Learning, 3 (6): 583-598. https://doi.org/10.1504/ijtel.2011.045449
[32] Carlos Prieto-Alvarez, Roberto Martinez-Maldonado and T. Anderson. 2017. Co-designing in learning analytics: tools and techniques. In J.C.H Lodge, J.C.H., L. Corrin ed. Learning analytics in the classroom: translating learning analytics research for teachers, Routledge.

[33] Carlos Prieto-Alvarez, Roberto Martinez-Maldonado, and T. Anderson. 2018. Co-designing learning analytics tools with learners. Learning analytics in the classroom: Translating learning analytics research for teachers. Abingdon-on-Thames, UK: Routledge.

[34] Ulla Richardson and Heikki Lyytinen. 2014. The GraphoGame Method: The Theoretical and Methodological Background of the TechnologyEnhanced Learning Environment for Learning to Read. Human Technology: An Interdisciplinary Journal on Humans in ICT Environments, 10

$39-60$ https://doi.org/10.17011/ht/urn.201405281859

[35] Maria Jesus Rodriguez-Triana, Luis P. Prieto, Alexandra Martinez-Mones, juan I. Asensio-Perez and Yannis Dimitriadis. 2018. The teacher in the loop: customizing multimodal learning analytics for blended learning. In Proceedings of the International Conference of Learnng Analytics and Knowledge, 417-426. https://doi.org/10.1145/3170358.3170364.

[36] Maria Jesus Rodriguez-Triana, Alexandra Martinez-Mones, Juan I. Asensio-Perez and Yannis Dimitriadis. 2015. Scripting and monitoring each other: Aligning learning analytics and learning design to support teachers in orchestrating CSCL situations. British Journal of Educational Technology. https://doi.org/10111/bjet.12198

[37] Priya Sharma and Michael J. Hannafin. 2007. Scaffolding in technologyenhanced learning environments. Interactive Learning Environments, 15 (1). 27-46. https://doi.org/10.1080/10494820600996972

[38] Marjatta Takala. 2006. The Effects of Reciprocal Teaching on Reading Comprehension in Mainstream and Special (SLI) Education. Scandinavian Journal of Educational Research, 50 (5). 559-576. https://doi.org/10.1080/00313830600953824

[39] Ravi Vatrapu, Chris Teplovs, Nobuko Fujita and Susan Bull. 2011. Towards Visual Analytics for Teachers? Dynamic Diagnostic Pedagogical Decision Making. 93-98. In Proceedings of the First International Conference on Learning Analytics And Knowledge - LAK '11, 93-98. Retrieved September 2nd, 2018 from https://dl.acm.org/citation.cfm?id=2090129

[40] Katrien Verbert, Erik Duval, Joris Klerkx, Sten Govaerts and José Luis Santos. 2013. Learning Analytics Dashboard Applications. American Behavioral Scientist, $57 \quad$ (10), $1500-1509$. https://doi.org/10.1177/0002764213479363

[41] John Vines, Rachel Clarke, Peter Wright, John McCarthy and Patrick Olivier. 2013. Configuring Participation: On How We Involve People In Design. In Proceedings of the SIGCHI Conference in Human Factors in Computing Systems - CHI'13, 429-438. https://doi.org/10.1145/2470654.2470716

[42] Alyssa F. Wise and Jovita Vytasek. 2016. Learning analytics implementation design. In Handbook of Learning Analytics, 151-159. https://doi.org/1018698/hla17013

[43] http://simon.buckinghamshum.net/2018/10/alasi2018-co-designinglearning-analytics-with-la-deck/

[44] https://zuyd.figshare.com/articles/Fellowship_Of_The_Learning_Activity _boardgame/9884279 